\title{
Feasibility Analysis of Policy Tool Allocation on Dalian Overseas High-Level Talents
}

\author{
*Bing $\mathrm{He}$
}

\author{
School of foreign language, Dalian Jiaotong University, DaLian, China \\ *Corresponding author e-mail: rachelhe2008@163.com
}

\begin{abstract}
Belt and Road initiative was put forward by Xi Jinping, chairman of the China in September 2013. Since then, China has been committed to promoting and building an Asian community with a huge economy. With the deepening of "one belt, one road" initiative, Dalian's geographical advantages as the center of Northeast Asia are constantly highlighted. Talents play an important role in economic and social development. With the acceleration of big data and Internet economy, the flow speed and scope of talents are expanding, and the role of overseas high-level talents introduction for the smooth implementation of national development strategy is increasingly prominent. The formulation of talent policy documents includes many policy tools of introducing, encouraging, cultivating and using talents. The context of talent policy includes five policy tools of guarantee, incentive, development, service and evaluation, which should run through the four links of talent management: introduction, use, retention and education. In combination with the location advantages of Dalian City, efforts should be made to optimize the development environment for attracting overseas highlevel talents, strengthen the mechanism construction for the introduction and use of overseas high-level talents. By summarizing and analyzing the policies of Introducing High-level Talents from developed countries such as Europe, America, Japan and domestic developed cities, our study intends to enlighten Dalian on the policy-making.
\end{abstract}

Keywords: one belt, one road, Dalian, overseas high-level talents, talent policy tools

\section{INTRODUCTION}

Since the second half of the 20th century, the internationalization of economic life has shown two modes of world economic development: economic globalization and regional economic integration. To optimize the allocation of resources in the world has become an objective demand for the economic development of all countries and regions. Countries are constantly adjusting and improving their economic policies in the direction of reducing trade and investment barriers. These measures promote the formation of the trend of economic globalization. However, due to the close economic strength among the major countries in the world and the geopolitical factors, in order to take the initiative in the fierce international economic competition and master the important economic resources, one or several regional countries set up a regional economic integration organization centered on themselves, which has become an important factor for each country to seek regional economic development and defeat its competitors [1] One belt, one road, Silk Road Economic Belt and Maritime Silk Road in twenty-first Century, were proposed by $\mathrm{Xi}$ Jinping, President of the country in 2013, during his visit to Central Asia and Southeast Asian countries. "One belt, one road" construction is the key to interconnection, including policy communication, facilities interconnection, trade flow, financing and common people's hearts. With the continuous optimization of China's economic structure, the acceleration of transformation and upgrading, new momentum is surging. China's economy has entered a new era of high-quality development. [2]

Scientific and technological innovation, talent gathering and knowledge economy have become the main support of economic and social development. With the rapid development of China's economy, the demand for talents is increasing. However, talent training, especially high-end talent training has a long cycle. In order to expand the high-level talent team in a short period of time and meet the economic development strategy of national economic globalization and regional economic integration, the introduction, application, reserve and training of overseas high-level talents, that is, the implementation and promotion of "introduction, use, retention and education" of talents, are particularly important. In 2008, the state listed the introduction of overseas high-level talents as a national strategic task.

Dalian is the important part of the economic circle of Bohai. It is a major gateway to China's opening to the north. Dalian has the unique advantages of radiating the three northeastern provinces, serving the whole country and facing Northeast Asia in the great blueprint of "one belt and one road". One belt, one road plan was introduced 
in September 2018 by the provincial Party committee and the provincial government of Liaoning. It opened up a new era of high quality development in Liaoning, which led the construction of "one belt and one road" to open up and promote the comprehensive revitalization. Dalian, as the international shipping center, international logistics center, international trade center and regional financial center in Northeast Asia, occupies the core position in the construction of "three cores, three zones, two corridors and two sides, seven ports and seven roads, two parks and two financing, one network and one bridge" in the overall plan. Under the trend of new opportunities and new driving forces, Dalian comprehensively implements the strategy of introducing overseas high-level talents. In 2015, five documents were issued, including several regulations of Dalian on supporting innovation and Entrepreneurship of high-level talents, 22 supporting implementation rules were formulated, and the " $5+22$ " talent innovation policy system was established, which pointed out the direction of talent introduction in Dalian. The recent issuance of several specific issues on the implementation of the " $5+$ 22 " talent policy, the implementation rules of Dalian high level talent identification, the implementation rules of Dalian local high level talent incentive and other documents comprehensively promotes and implements the implementation of Dalian's strategy of introducing overseas high-level talents.

Based on the perspective of application analysis of policy tools, with the help of demand theory and talent policy process theory, this paper analyzes the characteristics and feasibility analysis of tool selection and allocation of overseas high-level talent policy, so as to attract talents, retain talents and give full play to their value.

\section{DEFINITION OF OVERSEAS HIGH LEVEL TALENTS}

Overseas high-level talents mainly refer to high-level talents living abroad for a long time, which generally have the following characteristics: first, they have a good education background, live, study and work abroad for a long time, understand Chinese and foreign culture, and absorb overseas advanced culture, education and innovation technology; second, they have a relatively advanced industry-leading technology or concept, and have innovative thinking mode and scientific research ability Third, they are relatively unfamiliar with the domestic research environment or market regulation system and need a certain period of adaptation process; fourth, they are eager to realize their own value and find a sense of belonging.

\section{INTRODUCTION OF OVERSEAS HIGH-LEVEL TALENTS IN DALIAN}

With the national strategic planning, Dalian's talent policy provides a strong intellectual guarantee for Dalian's urban development and economic transformation. Since 2000, the project of "Overseas Students Pioneer Park" has been implemented, including the supplementary provisions of Dalian on the introduction of talents, several provisions of Dalian on the introduction of overseas students for continuous work, and administrative measures of Dalian on the introduction of overseas research and development teams. Since 2009, several opinions of Dalian on the implementation of overseas students' top talents returning to China and Entrepreneurship Project, interim measures of Dalian on the introduction of overseas high-level talents, medium and long term talent development plan of Dalian (2010-2020) and other projects have been successively carried out; in 2015, the detailed rules for the implementation of supporting talent policy innovation documents of Dalian have been issued " $5+22$ " talent policy system, comprehensive talents policy and overseas talents supporting policies, the implementation rules of Dalian overseas outstanding expert gathering project management project clearly pointed out the main direction of Dalian's introduction of overseas high-level talents in the new era, and Dalian's overseas talents policy advanced and competitiveness improved significantly.

According to the data in 2016, Dalian ranks among the top sub provincial cities in China in terms of talent introduction, with more than 95 million yuan invested by the municipal government, 220 foreign expert projects and 1500 foreign experts. At the same time of vigorously introducing talents, all departments ensure that all kinds of talents are used at the right time, in their own right place and in their best use in all aspects of talent training, introduction, use and management. [3]

There are still deficiencies in the introduction of overseas high-level talents. For example, the development environment for attracting overseas high-level talents is not optimized enough, including that the comprehensive strength of the city's economy still needs to be improved, and the city brand needs to be further strengthened; the number of overseas top talents needs to be further improved and the distribution of talents is unbalanced; and the overseas high-level talents still need to be highly valued. The mechanism of introducing and using talents to promote the city's international competitiveness still needs to be improved, including the weakening of the leading role of the traditional "government-oriented" concept in the market demand for talents; the stability of the incentive mechanism for the introduction of overseas high-level talents needs to be improved; and the reality of the contradiction between overseas and domestic high-level talents. In addition, we need to constantly improve the public service system for overseas high-level talents.

\section{SSUGGESTIONS ON THE INTRODUCTION OF OVERSEAS HIGH-LEVEL TALENTS IN DALIAN}

Through the study of overseas high-level talent policies of foreign and domestic big cities, it is found that these policies have their own realistic rationality. If we only draw lessons from the policies through simple comparison, 
the research conclusions are inevitably subjective. From the perspective of academic research, it has certain limitations. By using the multi-component analysis path of talent policy value (i.e. talent demand), talent management process and talent policy tools, this paper puts forward the characteristics of policy tool selection and configuration and the status of function realization suitable for the local characteristics, and further puts forward the adjustment and improvement of policy items.

\subsection{Demand based talent policy}

Maslow divides human needs into five levels, which are physiological needs, security needs, social needs, respect needs and self-realization needs. According to the demand theory, talent policy tools can be divided into three categories: one is "safeguard policy tools"; the other is "incentive policy tools"; the third is "development policy tools". The safeguard policy tool requires the government public service to relax the policy of overseas talents, reflecting the party and government's care and support for overseas talents. The administrative requirements of "hard selection" and "eight shares" should be cancelled, and the comprehensive evaluation of professional quality, knowledge level, professional skills and work experience should be emphasized. Ensure that domestic and foreign talents enjoy the same social insurance, medical insurance and retirement benefits. Effective implementation and long-term effectiveness of incentive policy tools are the key to policy-making. A long-term and diversified incentive mechanism is essential. Besides, it is not limited to financial awards, such as the selection of Xinghai Friendship Award and the selection of government special allowance; it is also necessary to pay special attention to the realization of personal intrinsic values and shared cultural values, such as holding regular symposiums to listen to the demands of overseas high-level talents, so that overseas talents are greatly encouraged in human dignity. Dalian should consider the particularity of overseas talents' identity and adopt the double track evaluation system. International standard salary will be given to overseas high-level talents.

However, it is necessary to constantly narrow the assessment standards and gaps between foreign and domestic talents, achieve integrated development, and provide the same opportunities for development and the same promotion platform, which not only solves the development needs of overseas high-level talents, but also solves the objective contradictions between overseas and domestic high-level talents.

\section{2 talent policy based on talent management process}

The process of talent management is generally divided into four links: introduction, use, retention and education. "Talent introduction" refers to the priority of introducing necessary or urgently needed talents based on the establishment of talent strategy and the development characteristics of the region. Explore the multi-channel integration mode of overseas high-level talents introduction, continue to play the brand effect of "China Dalian Overseas Students Entrepreneurship Week", "Dalian International Entrepreneurship and Innovation Summit", "China International Software and Information Service Fair" and other large-scale events for a long time, and take the opportunity of establishing overseas talents workstation in Silicon Valley to strengthen the concept of industrial economic development and strong market. And Dalian - liveable city concept will make overseas highlevel talents timely understand the city brand of Dalian. We can also introduce overseas talents through flexible policies, and implement the "talent introduction" policy through multiple channels and modes, including technical guidance, honorary consultants, weekend engineers, technology equity, cooperative operation, establishment of expert workstations, etc.

The policy of "using talents" refers to providing policy support or development platform for talents to give full play to their talents. At present, Dalian's private economy has a good momentum of development, its international and domestic competitiveness is constantly improving, and its demand for overseas high-level talents is growing day by day. According to the strategic needs of Dalian's development, we should encourage the establishment of club system, strengthen the establishment of exchange platform between overseas talents and domestic talents, and provide convenient services to help talents solve their worries.

"Retaining talents" is to optimize welfare treatment and development support policies, so that talents can have a sense of cultural identity and spiritual belonging. Integrate the resources of all functional departments of the government to form a complete and smooth service system or green channel. It can "one-stop" solve the problems of overseas high-level talents, social security, medical treatment, housing subsidies, house purchase, etc. Priority can be given to the shortage of overseas high-level talents. A "one-stop" service window is specially set up to provide "full program and nanny" services for overseas talents and their families to handle entry and exit, residence, settlement, schooling, policy consultation, project application, etc. Establish overseas high-level talent apartments, provide comfortable and complete green ecological communities for overseas high-level talents, set up overseas flavor restaurants, bars, cafes and other leisure and entertainment places nearby, and provide relevant policy measures for living convenience.

With reference to overseas, domestic and Dalian's overseas talent policies, they all have the characteristics of "focusing on introduction, ignoring cultivation". Overseas high-level talents are high-end talents with good education and professional skills. The demand for training and reeducation is not high, which is also one of the main reasons for the obvious lack of "talent cultivation" measures in the formulation of overseas talent policy. But policy making should provide free education and training 
supporting innovation and Entrepreneurship of highlevel talents in Dalian, March 31, 2015, http://rsj.dl.gov.cn/open government affairs / Dalian government talent work / $\mathrm{rcfw} /$ pages / policy interpretation of provisions on supporting innovation and Entrepreneurship of high-level talents in Dalian

Looking at the world to observe China's economic situation in an all-round way, at present, the world economic growth continues to slow down, China's economic growth is still leading among the major economies, and "the scenery is unique here" is still the mainstream view of international public opinion on China's economy. As the first driving force of rapid economic development, China's scientific and technological innovation plays an important role. Artificial intelligence technology, $5 \mathrm{~g}$ is widely applied and implemented in China from the concept to the world. And China is at the forefront of the world. Talent is the key element in economic and social development, and the foundation and guarantee of national and regional competitive strength. Economic integration and globalization accelerate the flow of talents in the world, which makes the introduction of overseas high-level talents highly valued by many countries and regions.

In the introduction of overseas high-level talents, the key to the implementation of talent policy function is to attach importance to the improvement and optimization of talent policy, constantly improve the quality of talent policy and the reasonable selection and allocation of talent policy tools. Close combination of talent demand and talent management "introduction, use, retention and education" process is conducive to the continuous optimization and improvement of talent policy. Dalian, in the extraordinary rhythm of China's development miracle, has become a wonderful movement. It's like a giant ship breaking through the waves along the high-quality development direction. The development is for the people, at the same time, development depends on the people, and development achievements are shared by the people. This is not only the outstanding embodiment of the superiority of the socialist system, but also the inexhaustible source of the vitality of China's economy.

\section{REFERENCES}

[1] National Information Center: annual report on China's sharing economy development (2019), February 28, 2019, https://baike.baidu.com/item/annual report on China's sharing economy development $\% 282019 \%$ 29/23298621?fr=aladdin

[2] China one belt, one road network: "one belt, one road" building special plan for scientific and technological innovation cooperation, https://www.yidaiyilu.gov.cn/zchj/jggg/326.htm.

[3] Dalian human resources and Social Security Bureau: policy interpretation of Several Provisions on
[4] Maslow A H.A Theory of Human motivation[J]. Psychological Review, 1941, (4).

[5] Wang Yaojun, Liao Zhongju. Overseas high level talent entrepreneurship policy system: text analysis and optimization suggestions [J]. China human resources development, 2019,36 (08): 60-68

[6] Chen Jie, ye Xiaogang, Lian xingshuo, Liu zuojing. Historical review and Prospect of high level talent policy in Guangdong Province -- Based on the analysis of policy text from 1978 to 2018 [J]. Science and technology management research, 2019,39 (21): 33-39

[7] Guo Yulin, Chu Fanjing. Problems and suggestions on regional policy of high-level talent introduction [J]. China Light Industry Education, 2019 (04): 59-64 + 80 